\title{
What went wrong? A critical reflection on educator midwives' inability to transfer education knowledge
}

\author{
Yvonne Botma ${ }^{*}$ Champion Nyoni \\ School of Nursing, University of the Free State, Bloemfontein, South Africa
}

Received: December 1, 2014

Accepted: February 27, 2015

Online Published: March 17, 2015

DOI: $10.5430 /$ jnep.v5n6p1

URL: http://dx.doi.org/10.5430/jnep.v5n6p1

\begin{abstract}
As part of a competency-based curriculum development exercise, educator midwives were required to apply the design principles of constructivism, constructive alignment, scaffolding and authenticity in the development of teaching and learning material for a newly approved curriculum. Through action research cycles, the facilitators and educator midwives reflected on possible reasons why they struggled to apply the mentioned principles in developing learning activities for students. The unit of analysis comprised the reflections of facilitators and 12 educator midwives. Ten of the 12 educator midwives were older than 40 years and all had qualifications and experience in midwifery and education. The action-reflection cycles contributed to improvement in the quality of the learning activities but application of the scaffolding principle remained a challenge. Failure of the educator midwives to transfer their learning raised concerns about their ability to facilitate deep learning. Considering the age of the group and the ingrained rote memorisation characteristic of education methods during their training made curriculum drift a real threat. Educator midwives struggled to integrate education knowledge into educational practice. Nursing schools that are in the process of changing their teaching paradigm may find this article useful to identify possible challenges and suggested solutions.
\end{abstract}

Key Words: Curriculum redesign, Curriculum drift, Theory-practice gap, Transfer of learning

\section{INTRODUCTION}

Curriculum development is an active and iterative process with the involvement of a wide array of stakeholders. A variety of contextual strategies in curriculum development are utilised globally although the nurse educator is usually at the core of the development and implementation process of curricula.

Current trends in health professions education have embraced a shift in the process of education. The shift in health professions education process results in the emphasis of teaching and learning and the overall outcome of the intended professional. ${ }^{[1]}$ Educational transformations in health professions education take into account contextual developments, expec- tations of future employers as well as the expectations of the graduating health professionals. The health professionals have to meet the needs of the society they serve, the employers' expectations and professional obligations that include being a life-long learner.

The International Confederation of Midwives (ICM) has made available various prototypical curricula for midwifery education in different regions of the world. The prototypical curriculum emphasises competence-based education (CBE) as a strategy for attaining the outcomes stated within the curricula. These competences are developed in consultation with a range of related stakeholders. Individual institutions have to align their midwifery curricula with the ICM proto-

\footnotetext{
* Correspondence: Yvonne Botma; Email: botmay@ufs.ac.za; Address: School of Nursing, University of the Free State, PO Box 339, Bloemfontein 9300, South Africa.
} 
type curriculum. ${ }^{[2]}$

The adoption of CBE as a strategy for teaching and learning within midwifery education highlights redirection in the whole education process of midwives. The nature and scope of the education process in CBE reflects a student-centred approach. ${ }^{[2]}$ At the core of this paradigm shift is the nurse educator who has to adapt her/his instructional methods to meet the underpinnings of CBE. ${ }^{[1]}$

\section{Background}

The facilitators were involved in the development of a CBC for a midwifery programme based on the prototypical curriculum of the ICM. The CBC was developed to replace the didactic teaching and learning strategy, which was contentdriven and had been utilised in midwifery training for more than twenty years. Midwifery educators where engaged in this development of the new CBC utilising Fink' ${ }^{[3]}$ " designdown, deliver-up" framework. Fink's framework states that in designing curricula the outcomes/competences should first be determined, then the assessment methods and lastly the learning activities. ${ }^{[3]}$ However, as the educator delivers the curricular, they deliver up, that is the educator starts with facilitating the learning activities, apply the assessment methods and lastly evaluate whether the students attained the outcomes/competences.

Before referring to research, the principles of constructivism, constructive alignment, scaffolding and authenticity, which underpin the process of curriculum design and possible implementation, warrant explanation. The application of the principles in the context of this study is discussed.

Constructivism is a common learning theory that has been applied to various settings of health professions education globally. ${ }^{[4,5]}$ The principle of constructivism highlights the need for students within midwifery to be able to actively make meaning of the information they acquire during training. Students are expected to interact with the environment from which they are learning and to build upon the experience they bring along to their learning experience. ${ }^{[6]}$ Learning is reoriented from being teacher-centred and teacher-driven to being student-centred and student-driven. ${ }^{[1,7]}$ Evidence of application in midwifery education should be highlighted in the nature of student learning activities which enhance the student's making sense and meaning of the science. The design of the student's learning activities should reflect the application of the constructivist learning principles, namely active engagement of the student, creating opportunity for the student to make meaning, and social interaction with peers and experts to validate constructed knowledge. ${ }^{[8]}$

Constructive alignment builds on the application of construc- tivism. Curriculum outcomes or competences, teaching activities and assessment must be aligned. Instructional alignment ensures a precise match between what is intended to be learned, what is taught, and what is measured, so that variation in pace of learning replaces variation in attainment, the essence of competency-based training. ${ }^{[5]}$ Scaffolding underpins the development and attainment of objectives and learning outcomes. This principle is based on moving in general from a known system to the unknown, the simple to complex maxim, and providing information when needed. ${ }^{\text {[9] }}$ In the current study, the design of the outcomes adapted and adopted from the prototypical curriculum from the ICM meant that the educators graded the outcomes at their level of complexity and the amount of time the student needed to be engaged for the mastery of each competence. Scaffolding highlights the need for foundational knowledge as required by the student to progress to the development of functional knowledge and to be able to perform an outcome in the context of a simulated or real environment. ${ }^{[10]}$ However, there is emphasis on building appropriate knowledge. The implication of these principles is well spliced in that one principle relates to the other. The educator allows the students to make meaning of what they have learnt while "taking a back seat" in the whole education process and assuming the role of an expert who only directs students in the creation of accurate meaning of the science being learnt. ${ }^{[11]}$ The educator's role is to enhance the building up of correct education or knowledge by the student.

Learning in class or in simulated environments has to be reflective of situations that are practical or real in the clinical environment. ${ }^{[11]}$ Authenticity is reflected in the activities in which students are involved for the attainment of midwifery competences. Learning outcomes and activities take into account the national health status and health delivery system. Implications of authenticity as a learning principle mean that the simulated, paper-based and/or work-integrated learning activities are based on environments, scenarios and cases that are reflective of what the real world of midwifery practice entails. ${ }^{[12]}$ Learning activities should also incorporate and reflect the current disease profile of the country in question.

Designing the curriculum was done in phases. The first phase involved the alignment of the ICM prototypical curriculum to the contextual requirements of the setting. The second phase involved the development of broad learning outcomes based on the specific competences derived from the ICM prototypical curriculum. These outcomes highlighted the major themes that are embedded in midwifery. The themes included Antenatal care, Labour and Childbirth, Post-natal care, Neonatal care and Research methodology. Monitoring the wellbeing of the mother and foetus during the antenatal 
period and recognising warning signs and symptoms that need referral are pivotal in reducing mother and child mortality. Midwives should thus be skilled in noticing and interpreting subjective and objective patient data and in making sound clinical judgments.

Development of assessment strategies was the next phase. A guiding question was, "What will be the evidence that the student is competent in ...?" Competence is determined through the midwives' performance in a certain context, for example he or she should be able to:

- notice clinical sign and symptoms;

- interpret the assessment findings;

- understand the relationship among the range of the patients' manifestations;

- make sound clinical judgment; and

- render appropriate care.

In addition, the student should be able to demonstrate critical thinking, clinical reasoning and sound judgment within a specific context. Authentic assessment within a specific context equates to integrated assessments. ${ }^{[13]}$ Although written tests and examinations are still needed to assess the foundational knowledge comprehensively and holistically assessment methods are needed to determine the competence of a student.

The educator midwives developed modules that reflected strategies which ensured attainment of specified outcomes. ${ }^{[1]}$ Five modules were developed, which correlated with the competences of the new competence-based curriculum.

The last phase of curriculum development included the design of activities reflecting the various knowledge levels, i.e., foundational, conditional, functional and metacognitive levels. These were highlighted as student activities to gain specified skills and content enabling them to complete the assessment task and therefore demonstrating their specific competences. This process of activity development was completed through the compilation of study guides or workbooks.

Initially, the educator midwives were divided into six groups with two people per group. The first activity involved the whole group working on one theme, namely antenatal care (ANC). Each group selected a sub-unit of the theme on ANC to work with. The task was to devise key activities that would portray the range of knowledge levels, thus enabling students to become competent. Almost a full day was accorded to each group to work on the sub-unit they selected.

On concluding the first day, the educator midwives presented the planned activities and learning material to the larger forum. The material presented did not meet the expectations of the facilitators because the underpinning principles highlighted throughout curriculum development were not reflected. Although the activities developed for student engagement partially reflected reality, the facilitators noted poor alignment of the activities to the assessment techniques highlighted in the preceding activity by the same group on the development of modules or assessment guides. Furthermore, the activities developed lacked gradual introduction and transition from foundational knowledge through to functional knowledge and performance of an outcome.

The main purpose of the inquiry reported in this article was to identify why the educator midwives were unable to apply the design principles in developing learning activities. The investigation used critical reflection techniques and action research.

\section{UNIT OF ANALYSIS}

All the phased activities within the curriculum development process engaged a cohort of 12 educator midwives from five schools of nursing in one African country with the following inclusion criteria: a minimum qualification of a bachelor's degree in nursing, midwifery as a specialist qualification, and an additional qualification in nursing education. It is standard practice in the country of research that midwifery educators must accompany students in clinical practice.

All the educator midwives had extensive experience in midwifery practice and at least four years' practising as midwifery educators in the five schools of nursing. These educator midwives formed the bulk of the faculty that was set to implement the new curriculum for midwifery and thus were purposively selected from their individual schools. The educator midwives worked with the facilitators from the initial phases of the $\mathrm{CBC}$ development. Initially and intermittently, the educator midwives received training and education related to the principles underpinning the curriculum development process, the philosophy and pedagogy in CBE and the overall curriculum development process. The two year curriculum development process involved the researchers alternatively presenting the principles underpinning CBE implementation to the educator midwives. Evaluation for understanding was through paper based activities and verbal discussions with the educator midwives on the underpinning principles. The educator midwives had demonstrated understanding of the underlying principles in CBE. Throughout the curriculum development process, the 12 educator midwives actively participated and shared their knowledge regarding constructivism and competency-based learning with the rest of the midwifery fraternity in order to promote 'buy-in' into CBC. The group of 12 midwives effectively used the four design principles that underpin the competency-based curriculum to convince stakeholders of the content and processes 
in the new curriculum.

The two authors facilitated the whole process from curriculum design to compilation of the learning activities. One of the facilitators was an educator at one of the schools of nursing while the other was a consultant from a university in the same region. Both facilitators are midwives.

\section{Methods}

Following a work session, ${ }^{[15]}$ the facilitators had reflective conversations during which they discussed their perceptions of progress and how they could influence the cognitive processes of the educator midwives. ${ }^{[16]}$ These reflective conversations contained elements of metacognition because the facilitators had high levels of self-awareness and thought about their perceptions and ideas. ${ }^{[17]}$ They consistently reflected on their actions and reactions as well as on what they could do differently in order to enhance the design process. Berg $^{[16]}$ defines reflexivity as a dialogue that examines what we know and how we come to know this.

In addition to the reflective activities of the facilitators, the participants wrote notes on how they experienced the process of designing the learning activities. However, the participants were first informed that the facilitators intended to publish an article on the process and experiences. It was also explained that by writing the notes and giving it to the facilitators the participants indicated their consent to participate.

\subsection{Research design}

Action research cycles were used to identify the possible cause(s) of why the educator midwives are not achieving the expected quality of work in designing student activities. The facilitators critically reflected on the possible challenges and devised and implemented plans to address the identified challenges. Action research as methodology is viewed as a "practice changing practice", and in this case we aimed firstly to improve the quality of the workbooks being developed and secondly to create educational knowledge through critical reflection on what was learned and the significance of such learning for future practice and research. ${ }^{[14]}$

The group met for four days to design the learning activities. Each day, after the group adjourned, the facilitators had reflective discussions and decided on the way forward. Two cycles are described.

\subsection{Identification of the challenge}

The first author facilitated the curriculum development process and had worked with the group for two years prior to the activity. She also introduced and explained the process that had to be followed to develop learning activities. A wide range of exemplar learning activities were shown during the orientation.

Both facilitators were discouraged when the participants presented the work they had done during the first morning. The activities that should have aimed to engage students with the learning material mirrored test or examination questions, were repetitive, and were at a low cognitive level. For example, instructions to the students were to read specified pages, watch a video and answer questions that followed. It was apparent that the learning material being designed was not engaging the students in creative ways and did not portray application of the four design principles of constructivism, constructive alignment, authenticity and scaffolding. At the end of the session, the facilitators were disheartened and realised that they were facing a challenge.

\subsection{Data analysis}

Each evening the facilitators met and reflected on what transpired during the facilitation sessions. During the reflective discussions, the facilitators served as sounding boards for one another. Feelings and observations were thoroughly explored and discussed in the search for possible explanations for the inability of the educator midwives to apply the four principles in designing learning activities. They then read the notes written by the nurse educators and triangulated the information. Based on their understanding of the days' happening they planned on how to approach the next cycle. The facilitators tried to make meaning of the process through literature that either support or contradict their interpretation of the process.

\section{Findings PER CYCLE}

In the next section, data generated by the facilitators and the educator midwives during the two cycles are described and discussed per cycle.

\subsection{First cycle}

Initially, the facilitators were distressed because they thought the process had been outlined clearly and that the educator midwives were conversant with the design principles. They thought it would be just a case of applying the principles in a different context. Furthermore, the examples given portrayed numerous types of learning activities and covered the full range of knowledge levels. Contrary to the expectation, the notes by the educator midwives revealed that they did not understand what was expected of them and they were confused. The following are excerpts from their notes:

"[I] was completely lost the first session as it was difficult for me to know what the expectation was. Kept on asking myself several questions regarding which format 
were we expected to follow, what does the competency denote?"

"The assignment was very difficult and unclear. I felt confused and unsure. After the group presentations I felt better and saw some light in the tunnel."

Through reflection, the facilitators came to the conclusion that the participants either had forgotten about the underpinning principles or could not apply them. We also considered the possibility that none of them had done any reading on the topic of competence-based curricula and the facilitation of learning in such a programme.

During the action research intervention, the educator midwives confirmed that they had not read anything pertaining to competence-based curricula and that they were completely reliant on the information provided by the facilitators. Consequently, we gave a brief overview of Fink's ${ }^{[3]}$ "design-down, deliver-up" strategy to promote significant learning. Furthermore, we reiterated that constructivism as learning theory emphasises that students should "make meaning" of experiences and learning content. As facilitators, it is the educators' responsibility to create situations and learning activities that afford students the opportunity to think and integrate information between components and between tasks. ${ }^{[8,18,19]}$

Scaffolding was again explained as a process that moves students from a well-structured problem to ill-structured applied problems, which encourage more elaborate and robust processing and integration of course concepts and content. ${ }^{\text {[20] }}$ The participating educator midwives were encouraged to integrate knowledge, skills and attitude components as foundational knowledge, and then progress to conditional knowledge with integration of clinical information, which culminates in functional knowledge as evidenced by sound clinical judgment. ${ }^{[21]}$

The facilitators concur with Moulding ${ }^{[22]}$ that knowledge is specific to the context, experience and circumstances; therefore, authenticity is of paramount importance. It is essential that students should be engaged in classroom activities that portray the reality of the clinical world, in other words, activities or paper cases should be authentic. Processes and information included or shared in the paper cases should reflect the ideal and correct way of doing because it encourages correct thinking patterns. One of the educator midwives had a "light-bulb" moment on authenticity when she declared, "... learning activities should bring the practice to the classroom".

\subsection{Second cycle}

During the second cycle, the paper cases or scenarios were much better developed and reflected comprehensive mid- wifery assessment information. The repetitive type of information with regard to assessing pregnant women or women giving birth would strengthen the thinking patterns ("habits of mind") of students when dealing with a real patient. A wide variety of activities to engage students with the learning content were incorporated, for example games, real documentation charts, videos, crossword puzzles, flow charts, mind or concept mapping, role-play, debating, storytelling and simulation. Participants' comments supported this observation:

"I thought I got the concept. We even had games and puzzles unlike the previous day. After the presentation, I learnt that we are still on the track."

"Deliberation on the designing down, delivering up further clarified how workbooks can be developed. It is clear that the workbook should enable the students to be self-directed and it can communicate with the user. It should reflect activity to help student acquire knowledge, skill and attitude before performing."

Although there was much improvement with regard to authenticity and variation of activities, scaffolding remained a challenge. Basic knowledge and skills that would enable students to progress from critical thinking to clinical reasoning were absent among the activities. The following comments confirm the facilitators' reflections:

"... [I] realised we had neglected the foundational level. We learned a lot and feel capacitated for the task."

"The experience was wonderful. My level of theoretical understanding of CBC (competency-based curriculum) and development of study guides has improved. Still challenged with the application component especially in ensuring that the foundational knowledge has been captured."

The activities that were developed did not reflect all the course content. The amount of work presented was also insufficient to resemble a workbook for a full semester course. This was evidenced by ten activities for a full postnatal module.

\section{Discussion}

Learning activities should stimulate students to understand and develop insight into the related theories from different disciplines. For example, students should be able to relate all the medical disciplines in order to get a "holistic" picture of the patient. Thus, the disciplines such as microbiology, pharmacology, sociology, psychology, anatomy and physiology all play a role in clinical manifestations and should be considered and understood. This integration of foundational knowledge is known as critical thinking. ${ }^{[21,23]}$ In her 
clinical judgment model, Tanner ${ }^{[24]}$ explains that competent nurses are able to notice deviations from the norm and can explain the manifestations, predict the progression of the condition, or explain how the interventions should alter the manifestations of the patient. An example of scaffolding in a midwifery course refers to being able to integrate and relate foundational knowledge (critical thinking) and then to link such knowledge with the subjective and objective data of a patient (clinical reasoning). This process of clinical reasoning and clinical judgment is very similar to the problem solving process of assessing, planning, implementing and evaluating in the nursing care plan, which has been implemented in the content-driven curriculum. The facilitators were baffled as to why the educator midwives could not demonstrate scaffolding in the planned activities as there were not that much difference between the two processes.

In addition to being really puzzled by this phenomenon, we as facilitators were also very concerned because we reasoned that, if midwifery educators are unable to incorporate the processes of critical thinking and clinical reasoning into the learning activities they are developing, they will also be unable to facilitate these thinking processes in the classroom and clinical setting. More unsettling was the idea that the problem of theory-practice integration does not lie with the inability of the students but rather with the inability of the educators to facilitate the process in students. A participant remarked:

" $\mathrm{CBC}$ is challenging and demands that a drastic change start with the nurse educators. The nurse educators however still need a lot of guidance in order to be able to effectively help the learners through CBC."

Kenner and Weinerman ${ }^{[25]}$ offer an explanation by stating that deeply ingrained rote memorisation and exacting repetition make it difficult for adult learners to change, regardless of the degree of error resulting from a flawed tacitly developed learning theory. Rote memorisation and repetition develop foundational knowledge that becomes part of the person's psyche and self-perception and enables the person to do a repetitive task the same way every time. ${ }^{[25]}$ However, facilitating learning in a competency-based curriculum requires from the educator midwives to explore different ways of examining and incorporating information. Participants who participated in the curriculum development process over the two years before the study clearly struggled in their exploration and internalisation of new information and processes.

Contributing to the limited internalisation of the design principles is the lack of self-directed and life-long learning. Although many of the participants had a qualification in advanced midwifery or even a master's degree, they might not have read any academic article pertaining to midwifery recently and might not have read any literature on competencebased education or curriculum development.

The combination of these factors sets the scene for curriculum drift. Curriculum drift is explained as the insidious process by which the curriculum returns to its pre-innovative state. ${ }^{[26]}$ Another factor which might have caused curriculum drift in this situation is the fact that many of the champions (12 educator midwives) will retire within the next five years.

\section{Conclusion}

The information gathered from two critical reflection sessions of the facilitators was triangulated with the notes made by the 12 educator midwives on their experience of designing learning activities. Our perceptions and those of the educator midwives were congruent. Stereotypical test and examination questions were developed initially. Later on, a large variety of activities were developed but the educator midwives still struggled to lead the students on paper through the process of meaning making regarding foundational knowledge and clinical reasoning. Scaffolding content and learning activities remained a challenge.

The specific context of the study was a limitation because the educator midwives came from a traditional African culture where the elders are respected and viewed as the leaders. Although it was not the aim of this study to generalise, other nursing schools that are in the process of changing their teaching paradigm from content-driven to either competenceor outcomes-based may find this article useful to identify possible challenges and suggested solutions.

We recommend that all the educator midwives be empowered to implement the new competence-based curriculum successfully, well realising that a mind shift is not made in a day or two. Aspects that should be addressed during the empowering process are:

- the curriculum design process of formulating outcomes or competences, as well as determining what should constitute the evidence of competence, and the learning activities of the student;

- the application of design principles, such as the underpinning learning theory, alignment, scaffolding and authenticity;

- designing stimulating authentic learning activities that will enable students to become competent;

- ensuring effective facilitation of deep learning; and

- designing valid and reliable complex-integrated assessments.

It is therefore imperative that follow-up sessions be scheduled or be made compulsory through the regulatory body. 
This can even be done through continuous professional development with a specified minimum number of units.

Future research should focus on the monitoring and evaluation of the implementation of the new competence-based curriculum. Another suggestion is that young educator midwives be involved in designing and developing new programmes because their rote and mechanical learning and teaching are not yet deeply ingrained. The challenge with senior people is that their tacit and rote learning is deeply ingrained and they struggle to adopt the new approaches. To be culturally congruent, senior people should be the champions of the change process but many of them will retire within a few years leaving the curriculum vulnerable to drift. Young people may be more receptive to the changes than more mature people and they may also be available for longer to champion the curriculum.

The quotation by Martin H Fischer comes to mind: The tragedy of education is played in two scenes - incompetent pupils facing competent teachers and incompetent teachers facing competent pupils.

Insufficient buy-in from the education fraternity and inadequate enabling of the educator midwives may render the process of curriculum redesign and implementation null and void. By taking heed of the suggestions formulated based on the lessons learned through reflection of the action research process, the obstacles to application may be overcome to ensure continuity and excellence in nursing education.

\section{ACKNOWLEDgeMENTS}

The authors appreciate the contributions of the critical reader, Dr Ruth Albertyn and of the language editor, Ms Jackie Viljoen, in improving the quality of the paper.

\section{CONFLicts OF InTEREST Disclosure}

The authors declare that there is no conflict of interest statement.

\section{REFERENCES}

[1] Malan S. The "new paradigm" of outcomes- based education in perspective. Journal of Family Ecology and Consumer Sciences. 2008; 28: $22-28$

[2] International Confederation of Midwives. Essential competencies for basic midwifery practice 2010. Available from: http://www. inte rnationalmidwives.org

[3] Fink L. A self-directed guide to designing courses for significant learning. San Francisco, CA: Jossey-Bass.

[4] Thistlethwaite J. Interprofessional education: A review of context, learning and the research agenda. Medical Education. 2003; 46: 58-70. PMid:22150197 http://dx.doi.org/10.1111/j.1 $365-2923.2011 .04143 . x$

[5] Jervis $\mathrm{L}$, Jervis $\mathrm{L}$. What is constructivism in constructive alignment? 2008. Available from: http://www.bioscience.heacademy/j ournal/vol6/beej-6-5.pdf

[6] Swing S. Perspectives on competency based medical education from the learning sciences. Medical Teacher. 2012; 38(8): 663-668.

[7] Harden R. Learning outcomes and instructional objectives: Is there a difference? Medical Teacher. 2002; 24(2): 151-155. PMid:12098434 http://dx.doi.org/10.1080/0142159022020687

[8] Kala S, Isaramalai SA, Pohthong A. Electronic learning and constructivism: A model for nursing education. Nurse Education Today. 2010; 30(1): 61-66. PMid:19573956 http://dx.doi.org/10.10 $16 / j$.nedt. 2009.06.002

[9] Van Merrienboer JJG, Kirschner PA, Kester L. Taking the load off a learner's mind: Instructional design for complex learning. Educational Psychologist. 2003; 38(1): 5-13. http://dx.doi.org/10. 1207/S15326985EP3801_2

[10] Kouwenhoven W. Competence-based curriculum development in higher education: Some African experiences. In M. Cantrell, M. Kool, \& W. Kouwenhoven (Eds.), Access \& expansion: Challenges for higher education improvement in developing countries. Amsterdam: VU University Press. 2010.
[11] Jonnaert P, Maciotra D, Morel J, et al. From competence in the curriculum to competence in action. Prospects: Quarterly Review of Comparative Education. 2007; 2(2): 187-203. http://dx.doi.o $\mathrm{rg} / 10.1007 / \mathrm{s} 11125-007-9027-9$

[12] Struing L, Bieman H, Mulder M, et al. The nature of study programmes in vocational education: Evaluation of the model from comprehensive competence-based vocational education in the Netherlands. Vocations and Learning. 2011; 4: 191-210. http://dx. doi . org/10.1007/s12186-011-9059-4

[13] South African Qualifications Authority. Guidelines for integrated assessment. Pretoria: Author. 2001.

[14] Wood L, Govender B. 'You learn from going through the process': The perceptions of South African school leaders about action research. Action Res. 2013; 11(2): 176-193. http://dx.doi.org/1 $0.1177 / 1476750313479411$

[15] De Vos AS, Strydom H, Fouché CB, et al. Research at grass roots: For the social science and human service professions (4th ed.) Pretoria: Van Schaik. 2011.

[16] Berg BL. Qualitative research methods for the social sciences (5th ed.). Boston, MA: Pearson. 2004.

[17] Banning M. Nursing research: Perspectives on critical thinking. British Journal of Nursing. 2006; 15(8): 458-461. PMid:16723953 http://dx.doi.org/10.12968/bjon.2006.15.8.20966

[18] Botma Y, Van Rensburg GH, Coetzee IM, et al. A conceptual framework for educational design at modular level to promote transfer of learning. Innovations in Education and Teaching International. 2013. http://dx.doi.org/10.1080/14703297.2013.866051

[19] Pascoe M, Singh S. "By the end of this course you should be able to ..." Towards constructive alignment in the SLP curriculum. The South African Journal of Communication Disorders. 2008; 55: 91110. PMid: 19485072

[20] Green GP, Bean JC, Peterson DJ. Deep learning in intermediate microeconomics: Using scaffolding assignments to teach theory and pro- 
mote transfer. The Journal of Economic Education. 2013; 44(2): 142 157. http://dx.doi.org/10.1080/00220485.2013.770338

[21] Chang MJ, Chang YJ, Kuo SH, et al. Relationships between critical thinking ability and nursing competence in clinical nurses. Journal of Clinical Nursing. 2011; 20(21/22): 3224-3232. PMid:21414054

[22] Moulding NT. Intelligent design: Student perceptions of teaching and learning in large social work classes. Higher Education Research \& Development. 2010; 29(2): 151-165. http://dx.doi.org/10 $1080 / 07294360903470977$

[23] Nursing Education Stakeholders. A proposed model for clinical nursing education and training in South Africa. Trends in Nursing. 2012;
1: 49-58.

[24] Tanner CA. Thinking like a nurse: a research-based model of clinical judgment in nursing. Journal of Nursing Education. 2006; 45(6): 204-211. PMid:16780008

[25] Kenner C, Weinerman J. Adult learning theory: Applications to non-traditional college students. Journal of College Reading and Learning. 2011; 41(2): 87-96. http://dx.doi.org/10.1080/1 0790195.2011 .10850344

[26] Wilson E, Rudy D, Elam C, et al. Preventing curriculum drift: Sustaining change and building upon innovation. Annals of Behavioral Science and Medical Education. 2012; 18(2): 23-26. 